\title{
FRAY ALBERTO E. ARIZA, O.P. ORGANIZADOR DE LA PROVINCHA DOMINICANA Y RESTAURADOR DE LA UNIVERSIDAD SANTO TOMÁS EN COLOMBIA*
}

(Recibido: Marzo 08 de 2011 Aprobado: Abril 29 de 2011)

William Elvis Plata Quezada**

\section{RESUMEN}

Basado en fuentes primarias escritas y orales, este artículo realiza un esbozo biográfico crítico del accionar público de Fr. Alberto Ariza O.P., tres veces provincial de los dominicos de Colombia y considerado uno de los bastiones de la consolidación del proceso de restauración y reorganización de la provincia dominicana en el país, incluida la restauración de la Universidad Santo Tomás. Busca dar un aporte a la construcción de la memoria histórica, tanto de la Orden de Predicadores, como de su Universidad, durante el siglo XX.

\section{Palabras Claves}

Dominicos - Fray Alberto Ariza, O.P. - Universidad Santo Tomás - Restauración - Iglesia Católica

\section{FRAY ALBERTO E. ARIZA O.P. ORGANIZER OF THE DOMINICAN PROVINGE AND RESTORER OF THE SANTO TOMÁS UNIVERSITY IN COLOMBIA}

\section{Alistrac}

Based on written and oral primary sources, this article makes a critical biographical outline of the public actions of Fr. Alberto Ariza O.P., three times provincial of the Dominican of Colombia and considered one of the bastions for the consolidation of the process of restoration and reorganization of the Dominican province in the country, including the restoration of the University Santo Tomás. It intends to give a contribution to the construction of the historical memory of the Order of Preachers, as well as of his University, during the 20th century.

\section{Keywords}

Dominicans - Albert, Ariza O.P. - St. Thomas University - Restoration - Catholic Church

\footnotetext{
* Este artículo es producto de un proyecto de investigación desarrollado entre 2001 y 2005 bajo el liderazgo de la Hna. Blanca Ligia Perilla (Q.E.P.D.) y que tuvo como fin la recuperación de la memoria histórica de la Congregación Hermanas Dominicas de Betania. El autor agradece a las personas que contribuyeron, con su memoria hecha relato, a reconstruir la historia que se cuenta en estas páginas.

** Doctor en Historia (Facultés Notre-Dame de la Paix, Academia U. Católica Lovaina, Bélgica). Profesor de la Escuela de Historia de la Universidad Industrial de Santander, Bucaramanga, Colombia. Miembro del Instituto Colombiano para el Estudio de las Religiones - ICER. Coordinador del nodo UIS del Grupo de Estudios del Hecho Religioso "Sagrado y Profano". e-mail: weplataq@uis.edu.co
} 


\section{Introducción}

En 1910 la Provincia Dominicana de Colombia fue oficialmente restaurada, luego de superar la mayor crisis sufrida en toda su historia'. El proceso de restauración, sin embargo, fue lento, dificultoso y lleno de altibajos. Dicho proceso había iniciado en 1881, cuando previo retiro espiritual, un grupo de frailes liderado por Fr. Buenaventura García O.P. (1826-1915), declararon restaurado el convento de Nuestra Señora del Rosario de Chiquinquirá. Tras unos años al frente, García cedió su liderazgo a Fr. Saturnino Gutiérrez O.P. (1835-1911), párroco de Villa de Leyva, quien ostentó el cargo de Vicario Provincial.

Lo que siguió fueron años difíciles para el proceso restaurador. Además de la reticencia de varios religiosos "viejos" a vivir en conventos, la mayoría de los antiguos claustros estaban en manos de entidades estatales, con pocas esperanzas de recuperarlos. Sólo el convento de Chiquinquirá no se había perdido en la práctica; fue por ello que se convirtió en epicentro, no sólo del proceso restaurador, sino de la misma provincia hasta bien entrado el siglo XX. El otrora gran convento "madre" de Nuestra Señora del Rosario de Bogotá estaba ocupado por oficinas gubernamentales; algo similar pasaba con el convento de Santo Domingo de Tunja, convertido en cuartel. Así mismo, el de San José de Cartagena era la sede del seminario diocesano.

Para completar, pocos querían ser dominicos. Las nuevas comunidades religiosas que llegaban a Colombia (salesianos, lasallistas, vicentinos, redentoristas y eudistas, entre otras) la mayoría de ellas fundadas en el siglo XIX, en Italia y Francia, eran mucho más atractivas entre la juventud; eran dirigidas por clérigos y religiosos extranjeros llenos de vigor $y$ proyectos. Aún los jesuitas, que habían sido restaurados, iniciaban un proceso de crecimiento y expansión acelerados, con el apoyo de las elites y autoridades gubernamentales.

Pese a los obstáculos, en 1910 la Curia Generalicia aprobó la restauración de la provincia dominicana de San Antonino de Colombia, tras el sucesivo restablecimiento de los conventos de Tunja (1903) Bogotá (1905) y Villa de Leyva (1909). El decreto correspondiente se emitió el 10 de junio de 1910, firmado por el Maestro Fr. Jacinto M. Cormier. En tal decreto se nombró como primer provincial a Fr. Vicente María Cornejo (1863-1912), quien ya ejercía como vicario desde junio de 1907. Cornejo era un panameño que se había formado en España y había llegado, junto con otros religiosos en la década de 1890 para contribuir al proceso de restauración de la provincia.

Aunque, por fin en 1910 la comunidad dominicana establecida en Colombia había recuperado el título de "Provincia" formal, fueron necesarias varias décadas antes que tal proceso se consolidara y se lograra una efectiva expansión. Las razones fueron varias:

En primer lugar, la ausencia de un proyecto. Durante la época colonial, la Orden había tenido como claves la evangelización de indígenas, el estudio teológico y lingüístico, la educación de criollos a través del Colegio Universidad Santo Tomás y la predicación popular y la formación de cofradías y hermandades, que a la postre le representaron bastiones que le permitieron influir con éxito entre las élites sociales y sectores populares. En esta nueva época no se vislumbraba aún un norte. Los religiosos, en su mayoría boyacenses, y formados en doctrinas tradicionalistas e intransigentes en boga, se dedicaban fundamentalmente a la pastoral popular desde el Santuario Mariano de Chiquinquirá y a una activa participación política a favor del Partido Conservador, llegaron incluso a ser parte de los directorios de este partido en Boyacá y Cundinamar- 
ca. Su preparación teológica era baja y existía un desconocimiento de ciertas costumbres y prácticas de rigor de la Orden. La indisciplina y las disputas internas arreciaban; varios conventos restaurados, como Santo Ecce-Homo, Popayán, o Villa de Leiva, tuvieron que cerrarse o rebajar su condición a casas conventuales, y las obras abiertas en Santa Marta y Zapatoca (Santander) se extinguieron al cabo de unos cuantos años, en medio de polémicas.

Para completar, el proceso restaurador se orientó en perspectiva conservadora: es decir, buscar recuperar el pasado, un supuesto pasado glorioso, que se añoraba con ardor, sin entender que ya no existía y no volvería nunca más.

Fue necesaria una generación de frailes que irrumpió a finales de la década de 1930. Dicha generación estuvo indiscutiblemente liderada por Fr. Alberto Ariza O.P., quien, junto con un grupo de dominicos franceses de reciente arribo al país, generaron las condiciones necesarias para que la comunidad dominicana se reorganizara en claves de futuro y tuviera de nuevo un norte, que se fijó en la misión, la actividad social y, sobre todo, la restauración de la Universidad Santo Tomás, hecho que se consuma en 1965. Lo paradójico fue que el líder era alguien que miraba al futuro "anclado en el pasado", como él mismo lo definió.

\section{Primeros pasos}

Fray Alberto Ariza nació en La Aguada, provincia de Vélez, Departamento de Santander, Colombia, el 13 de octubre de 1903 en el hogar conformado por Epaminondas Ariza y Tecla Sánchez. Al ser bautizado lo llamaron como su padre (Téllez, 1993:23). Como la mayoría de los dominicos de su generación, el futuro provincial de la Orden de Predicadores en Colombia provenía de origen humilde, y como era normal en una familia campesina de esta región, fue formado en un ambiente de total respeto por los valores y tradiciones católicas (Téllez, 1993:26).

En la única escuela de La Aguada, Epaminondas Ariza hijo inició su formación académica, allí hizo sus estudios primarios. Sin embargo, la falta de un centro de educación media obligó a retrasar su proceso educativo. Sólo, gracias a la oportunidad brindada por la Orden Dominicana, Epaminondas pudo continuar sus estudios formales. Tenía 18 años cuando salió de su pueblo para ingresar a la escuela apostólica que los frailes tenían en Chiquinquirá, donde adelantó la secundaria. En la misma ciudad, pero en el convento de Nuestra Señora del Rosario realizó, más adelante, sus estudios de filosofía y teología.

El joven Epaminondas rápidamente se familiarizó y se comprometió con la vida disciplinada, exigente, piadosa y estricta -muy estricta- inculcada por sus formadores (Téllez, 1993:26), lo cual marcó su personalidad y su proyecto de vida.

Al profesar en la Orden (1925) solicitó agregar a su nombre el del gran maestro medieval, San Alberto Magno. Desde entonces se le conocerá como Fray Alberto Ariza. El 29 de noviembre de 1931 fue ordenado sacerdote.

\section{Coordenadas políticas}

Antes de abordar el trabajo de Ariza como organizador e intelectual, es importante dejar en claro primero en qué coordenadas ideológicas se movió.

Tales lineamientos no son otros que los dados por el tradicionalismo católico, en sus versiones integristas e intransigentes, que pulularon por la Iglesia Católica a partir de la segunda mitad del siglo XIX, amparada en las encíclicas antimodernas de los papas Pío IX y Pío X, especialmente. Ariza creció mientras las historias de los ataques liberales a la institución eclesiástica y a su querida Orden religiosa, las declaraciones episcopales que afirmaban 
solemnemente que el liberalismo era pecado mortal y las consignas anticomunistas de los Papas Benedicto XV y Pío XI (Cifuentes, 2004; Arias, 2003).

Y si la Iglesia colombiana sobresalía por sus notables rasgos conservadores, los dominicos de nuestro país eran uno de los grupos eclesiales más beligerantes al respecto. No es un secreto la fuerte alianza que existía entre ellos y el partido conservador, especialmente en el Departamento de Boyacá, donde llegaron a liderar directorios de dicho partido. Ariza, repetimos, bebió de esas fuentes, se crió en ese ambiente dualista; sentía que en el mundo había una lucha entre dos fuerzas: una, el bien, expresada en los dogmas tradicionales del catolicismo, liderada por el Papa y ayudado por sus "comandantes": los obispos, las órdenes y las comunidades religiosas; la otra fuerza era el mal, representada en las ideologías modernas, en el mundo moderno, exponente de una falsa libertad, destructor de todo lo religioso, de la dignidad del hombre y enemigo de Dios.

Finalmente, Ariza creció bajo un pensamiento que añoraba el "idílico" pasado colonial de su Orden Dominicana, la "grandeza" de la misma y se lamentaba ante las desgracias sucedidas en el siglo XIX y la debilidad y dificultades que atravesaba a comienzos del siglo $X X$. Él mismo, en una alocución a los frailes estudiantes en 1960, afirmó:

iAnclados en el pasado! iEsto que quiere alegarse como un baldón, sea para nosotros un timbre de legítimo orgullo! iAspiremos a ello! iAspiremos a ser fieles a nuestra tradición, no perdamos de vista la roca de donde hemos sido cortados! (Ariza, 1960, p.12)

Por ello uno de sus propósitos como dirigente y escritor fue buscar el "engrandecimiento" material e intelectual de la Provincia y tratar de recuperar el espacio perdido en la sociedad y en la
Iglesia. Puede decirse que sus acciones estuvieron orientadas generalmente de cara al pasado, no al futuro.

En esta lógica tampoco debe extrañar el gran sentido combativo de este fraile y su automática alineación con las huestes conservadoras pues llegó incluso al compromiso político. En ello las fuentes coinciden perfectamente, sin dejar espacio a la duda.

En esa época entre las dos guerras y después la segunda guerra mundial, había un poco una visión hispanófila muy marcada en él, con ciertas diferencias con el pensamiento católico francés de vanguardia; muy fiel a la teología y a la eclesiología del Papa Pío XII. (...) los mismos jesuitas y los franciscanos son del mismo talante del padre Ariza; es toda una estructura mental de una postura de la jerarquía y de los superiores provinciales de aquella época en Colombia frente a la modernidad, frente a los movimientos laicos, frente al comunismo, frente a una democracia muy amplia. ${ }^{2}$

Al igual que muchos frailes de la Provincia, fue notoria su gran simpatía por el franquismo y falangismo españoles, implantados tras la guerra civil española en la década de 1930. Un testimonio nos refiere al respecto:

Todos, casi todos los frailes, con rarísimas excepciones eran germanófilos. iAy! Los padres franceses sufrieron aquí y el padre Ariza se distinguió por la defensa también de Franco en España y no se qué y tanto e igual que Báez y tanto que el gobierno español, le dio una condecoración al padre Ariza que se llama Isabel la Católica. ${ }^{3}$

Su compromiso político a favor del partido conservador y en contra del liberalismo lo llevó a choques con el gobierno liberal de entonces, y fue criticado incluso por frailes tan conservadores e integristas 
como él. Fr. Enrique Báez, fraile historiador de la primera mitad del siglo XX, dice en su Arcano de la Provincia, lo siguiente:

El padre Ariza hubiera terminado con mucha gloria (su primer provincialato) si no hubiera tropezado con escollos que no supo evitar. En efecto, fue un dinámico propulsor de obras que pocos hubieran llevado a cabo (...) pero se le presentaron dificultades que no supo vencer. (...) La política que tanto cultivó, cuando fue director de Veritas lo llevó a ser áulico de la dirección Conservadora, hasta el punto de ser acusado por el gobierno liberal, como conspirador (Báez, ¿1950?, p. 519)

Sin embargo, hacia 1946, Ariza rompió abruptamente sus compromisos con el partido Conservador, debido a que sus líderes no lo apoyaron en su disputa por el templo de Santo Domingo ${ }^{4}$, con los gobiernos de Alfonso López Pumerejo y Alberto Lleras. La ruptura de Ariza significó igualmente la separación oficial de los frailes colombianos de su tradicional nexo con la política partidista y eleccionaria. Un fraile contemporáneo nos cuenta sobre ello:

Con la venta del convento de Santo Domingo, mandó una circular, en la que decía que los frailes tenían que tirar su posición con relación al partido conservador, que no quería que lo siguieran a pie juntillas. (...) ... En la venta del convento de Santo Domingo (sic) los liberales fueron los que defendieron al padre Ariza y los godos fueron los que los atacaron; sobre todo Laureano Gómez y entonces, una vez vino el partido conservador, el jefe del partido conservador a pedirle la contribución al padre Ariza, porque parece que les daban contribución económica al partido conservador y les dijo: iNo sean sinvergüenzas! iDespués de que me atacaron ustedes...! ${ }^{5}$

La ruptura con el compromiso político no significó el abandono de las ideas con- servadoras y tradicionalistas. Estos elementos de su pensamiento los mantuvo toda su vida y marcó sus proyectos, sus actos, sus escritos y sus realizaciones.

\section{Coordenadas religiosas}

De acuerdo, en gran parte, con la lógica anterior, el pensamiento de Fray Alberto Ariza en el ámbito específicamente religioso tuvo dos ejes: su amor a la Virgen María, y su preocupación por la vida religiosa consagrada, encauzados ambos por la corriente tradicionalista católica.

Lo primero se manifestó por la vivencia, desde sus años de infancia, del Rosario y la devoción que tenía a la Virgen de Chiquinquirá, la cual ayudó a propagar en sus escritos. Continuamente realizaba consagraciones a la Virgen y desde un comienzo encomendó su propia vida sacerdotal a la protección de María. Fueron recordadas las coronaciones simbólicas realizadas a las imágenes de la Virgen de Chiquinquirá y de la Virgen del Rosario, conocida como "Virgen de la Conquista", que se conserva en la iglesia de Santo Domingo, en Bogotá.

Lo segundo se refleja en su accionar público y privado para sublimar este estilo de vida, organizarlo y disciplinarlo. Para él, la vida religiosa era un "apartarse del mundo" para la dedicación exclusiva a Dios, un estado de vida privilegiado para hallar la santidad y hacer la voluntad Divina, que debía ser resaltado en cada detalle, como el cambio del traje civil por el vestido religioso, que significaba dejar su actividad mundana y tomar la figura de un ser consagrado totalmente al quehacer celestial (Téllez, 1993, p. 31).

Pero al considerar la vida religiosa como una "obra total del amor de Dios", gracia de elección, a este fraile le preocupaba que quienes la asumieran, fueran sinceros en su decisión y estuvieran dispuestos a "realizar los excelsos designios de Dios con celo y perseverancia, 
teniendo en Dios y su Reino la razón de ser de nuestra profesión". (p. 28) En ello Ariza mostró su sentido de pragmatismo y disciplina, al romper definitivamente con la costumbre de "criar" niños en los conventos, práctica común hasta las primeras décadas del siglo $X X^{6}$; para él la vocación debía probarse y ser fruto de la madurez, no de la costumbre.

Estos pensamientos se manifestaron en un intento por rescatar la vida contemplativa como parte fundamental de la misión de la Orden, algo que en su tiempo las corrientes "progresistas" cuestionaban. Ariza no aceptaba que los dominicos irrumpieran abiertamente en apostolados "de base" y descuidaran la vida y disciplina monásticas.

El mundo moderno intenta disimular con el ruido espectacular su carencia de sustancialidad. Hasta el claustro religioso llega la algarabía que reclama un así llamado apostolado de la presencia que las más de las veces no es sino la exhibición de la propia vanidad. (...) Fácilmente ponemos oídos a esas extrañas sugerencias que impresionan nuestra superficialidad, y nos van convenciendo de que permanecer en la disciplina de nuestra vocación es permanecer anclados en el pasado, es quedarnos retrasados, es no estar al día. ¿Qué responderá a ello nuestro Santo Fundador? (Ariza, 1960, p. 12)

Fue por iniciativa suya que se intentó restaurar el antiguo convento del EcceHomo $^{7}$ y establecer allí una comunidad que viviera en contemplación, estudio y oración. Asimismo, el nuevo convento de Santo Domingo ${ }^{8}$ fue diseñado de manera tal que invitara al fraile a vivir en solemne recogimiento ${ }^{9}$; frecuentemente se le vio criticar los nuevos conventos construidos en años posteriores, por su estrechez, pero sobre todo, porque estaban diseñados de acuerdo a parámetros "mundanos", los cuales según él, buscaban "eliminar el ambiente tradicional para que no quede ni el recuerdo de nuestra herencia" (p. 1, 528).

De igual forma, Fray Alberto Ariza buscó que los frailes fueran disciplinados en el cumplimiento de sus deberes religiosos y no perdieran el espíritu de oración, con modelos tradicionales, por supuesto. Para él, “la máxima calamidad que le puede sobrevenir a una comunidad religiosa y de la cual se siguen las demás desgracias, es la inconsistencia de las obligaciones inherentes al estado religioso" (Téllez, 1993, p. 28).

Para él la Orden de Predicadores sería fiel a su misión en la medida que respetara y siguiera su tradición monástica, heredada de la Edad Media. Decía al respecto que:

mientras sea cierto que el Evangelio necesita de Apóstoles santos para que su mensaje sea eficaz, será cierto también que los medios señalados por Santo Domingo a la Orden no podrán ser suprimidos ni cambiados sustancialmente, como no puede serlo el Evangelio mismo (Ariza, 1960, p. 10)

Finalmente, en una faceta que puede considerarse "aperturista" (aunque siempre según experiencias del pasado colonial) Fr. Alberto Ariza promovió la integración de los religiosos. En esta perspectiva hizo parte del grupo que gestionó la creación de la Conferencia de Religiosos de Colombia (CRC) y fue su primer presidente. Organizó además el primer Congreso Nacional de Familia Dominicana, celebrado en 1952 en el nuevo convento de Santo Domingo, en Bogotá. A partir de entonces, el término "Familia dominicana" volvió a escucharse por los oídos de los seguidores del ideal de Domingo de Guzmán en Colombia.

\section{Organizador y constructor}

Ariza pronto tuvo como uno de sus objetivos de vida, la defensa de los intereses de su comunidad dominicana 
y buscó engrandecerla de acuerdo con su particular modo de ver el mundo. Sin exagerar podemos decir que la Provincia dominicana era una cosa antes y otra después de sus provincialatos. Por eso es coherente afirmar que Ariza constituye el último y uno de los más importantes restauradores de la Orden en Colombia.

\section{Un "sol" que eclipsaba a otros}

Para lograr su objetivo, se basó en su franqueza, laboriosidad, sobriedad y fuerte personalidad, de modo que, como afirma Fr. Luis Téllez, "en su lucha por restaurar los valores de la vida religiosa y la Orden, con frecuencia se torna urticante e incisivo, pero frentero y 'ansioso de altura'" (Téllez, 1993, p. 33).

Por otra parte, en ello, nuestro fraile se caracterizó por su autoritarismo, centralismo y hasta individualismo. Nunca admitió ni aceptó opiniones divergentes a la suya y los compromisos de la comunidad los asumía como asuntos personales. Puede decirse que Ariza supo muy poco el significado del trabajo en equipo. Fr. Carlos Mario Alzate, historiador, nos ilustra muy bien al respecto:

Es una figura solitaria, en la que no encontramos un equipo de trabajo, ni unos compañeros que de alguna manera soportaran ese dinamismo de él y mucho menos unos sucesores que pudieran haber tomado su lugar cuando él empezó a declinar. Pareciera que él, por espacio de 30 años por lo menos, brilló como una estrella solitaria y manejó la provincia con un criterio absolutamente personalista y autoritario; ciertamente con un gran amor a la Orden, una actitud apologética contra los enemigos externos y trenzado en polémicas muy grandes y muy desgastantes, poniendo las bases para lo que es la Provincia hoy ${ }^{10}$.

Ariza, quien andaba bien enterado de lo que pasaba en los altos círculos de la
Iglesia colombiana y en Roma, no dudaba en intervenir, en utilizar a terceras personas para gobernar a la sombra. Llegó a influir en la elección de provinciales, e imponer ideas suyas como decisiones de capítulo. Fr. José de Jesús Sedano nos comenta que Ariza quiso hacia 1960, llevarlo al provincialato y, a la vez, comprometerlo a su causa.

Me fui donde Ariza y le dije: bueno, sé que usted me tiene como candidato para provincial en 1960, entonces me dice: 'sí'. 'Acepto', le dije yo, 'pero no seré provincial para uno solo, seré provincial de todos (...).' iY se le acabó el candidato! (...)

(...) Entonces después él me encontró y me dijo: 'iAy! Nos tocó elegir a otro' -así hablaba- 'y nos tocó elegir a otro, al padre Claro; Claro, iComo la mula se echó!' Me dijo a mí. Entonces, yo le dije: 'pero lo que pasaba padre Ariza, era que esa mulita no quería tapa-ojos. ${ }^{11}$

Con Ariza, de acuerdo a los parámetros en que se formó, no había términos medios, o se estaba con él o contra él. Ariza, tras bambalinas, influyó en que se hiciera un ataque a los frailes que seguían orientaciones social-demócratas ${ }^{12} \mathrm{o}$ de la línea del Vaticano II. El propio Sedano fue uno de los afectados:

El influyó muchísimo en nosotros; estábamos trabajando con los laicos de santo Domingo, en la hermandad de santo Domingo y la revista actualidad cristiana; nos acusaron con el provincial y después nos acusaron a Roma, provocaron visitas de Roma, no encontraron mucha cosa los visitadores, vino el mismo Maestro, les dio su gusto a ellos y nos sacaron a nosotros $^{13}$.

\section{Ejes de su trabajo administrativo y pastoral}

Antes del ascenso de Fr. Alberto Ariza, la Provincia, restaurada desde Chiquinqui- 
rá, se había dedicado a la pastoral popular, promocionaba la devoción a la Virgen del Rosario. Esto no satisfacía del todo a las nuevas generaciones $\mathrm{ni}$, al parecer, a las autoridades de la Orden. EI Maestro General quería ampliarle horizontes a la misma, pues la veía muy estancada y Fr. Alberto surgió como una figura fresca y pujante, ideal para ese propósito. EI énfasis de su administración iba a ser la construcción material de la Provincia y el afianzamiento en el mundo educativo e intelectual. En un segundo lugar estaba la formación de los frailes y en un tercer puesto, la misión evangelizadora.

En la última cuestión vale decir que Ariza no se caracterizó precisamente por dotes pastorales. Según sus contemporáneos, no era un buen predicador y además le disgustaban las misiones, el trabajo catequético y la evangelización de base:

Yo no encuentro en el proyecto del padre Ariza al margen de toda su obra -sobresaliente sin duda- algo extraordinario, un proyecto intelectual, un proyecto evangelizador. De pronto leemos en categorías actuales de forma obviamente injusta en la época de él; pero yo veo que en esa época ya había comunidades, pienso en los salesianos, o en los jesuitas, que ya abrían nuevos espacios y preguntándose por el tipo de predicación y de presencia, yo creo que los dominicos estábamos en otro clima, un poco con el modelo español, pienso yo. El padre Ariza con el general (de la Orden) García Paredes, demuestra un poco la visión que él tenía de los dominicos, como unos monjes predicadores notables de cartel, según la época, pero no como movilizadores de la conciencia colectiva o como lideres sociales; o como una teología escolástica, polémica, apologética, pero en ningún momento creativa; yo no encuentro aquí ningún fulgor del padre Lagrange ni ninguna resonancia de Saulchoir, de la escuela de teología francesa; no la hay; no encontramos aquí ninguna cátedra que nos permita decir que había empatía de los dominicos colombianos con lo que ya los franceses escribían, los alemanes en los años 30 y 40 o que los escritos del padre Chenu o del padre Congar, tuvieran alguna mínima acogida; se da más bien al final de los años 60 cuando ya él (Ariza) había declinado y rompe ya la teología moderna y empieza a estudiar si y una pequeña elite de frailes sale a estudiar, pero no creo que, pienso que no fue obra del padre Ariza ${ }^{14}$.

Ariza siempre buscó permanecer en Bogotá, en el centro, o viajar por Europa, y nunca quiso ir durante períodos largos a la periferia, por ejemplo, a las misiones del Catatumbo. A esta, sólo fue a celebrar una Semana Santa, en los últimos años de su vida, en agradecimiento a Dios por una mejoría en su salud ${ }^{15}$. Cuando en la década de 1960 se le asignó a la naciente casa conventual de San Martín de Porres en Cúcuta, puede observarse en unas cartas dirigidas a María Teresa Benavides, un tono molesto, pero resignado, por esa decisión ${ }^{16}$. Tampoco le interesaban mucho las celebraciones con multitudes.

Su énfasis, repetimos, estaba en los proyectos materiales, visibles; aquellos que impactaran en la sociedad y en la Iglesia, preferentemente aquellos a los que se pudiera poner placa conmemorativa, una condecoración o un sello editorial. Fr. Enrique Báez, en una de sus últimas páginas sobre la "Crónica de la Provincia", inédita, compartía esta opinión y afirmó lo siguiente:

Debemos ser justos y apreciar la obra desde sus diversos puntos de vista. En el orden moral apenas alcanzamos a dibujar algunas mejoras, atendiendo a que este gobierno se ha dedicado con preferencia al mejoramiento material y económico, cual no lo habíamos visto en administraciones pasadas; tanto que en ocasiones 
pensamos si se hubiera abarcado demasiado" (Báez, ¿1950?, p. 799)

Y enumera sus logros como Provincial.

- Corrigió las malas administraciones del convento de Chiquinquirá, cuando el provincial decidió intervenir sus bienes y administrarlos de manera directa.

- Vendió una hacienda llamada "Santo Domingo de Varela", propiedad del convento, y con ella se compró el terreno y construyó el colegio de Santo Tomás de Aquino.

- Compró de un campo "Caleruega", en el vecindario de Usaquén, junto al noviciado de las Hnas. Terciarias Dominicas.

- Creó del colegio Liceo Frassati, en la vicaría de Marly. (1942), “que será el grano de mostaza de nuestra universidad en la capital".

- Fundó la revista Anales de la Provincia de San Antonino como órgano oficial de la Provincia.

- Abrió la misión en el Catatumbo.

- Inició la apertura de casas en Barranquilla y Cúcuta (Báez, ¿1950?, p. 799800).

En sus períodos al frente de la Provincia (1940-45, 1946, 1949-53, 1953-57), Ariza dirigió o promovió además de lo mencionado, la construcción del colegio Apostólico Jordán de Sajonia (19541956), fundó las casas dominicanas de Cúcuta y Bucaramanga (1944) y de Cali (1953) y la prelatura de San Luis Bertrán del Catatumbo (1945).

Tantas realizaciones y proyecciones en tan poco tiempo, indica que Ariza tenía todo un "plan" de reorganización de su comunidad desde mucho antes de llegar al poder en la Provincia. El fue uno de los primeros en abandonar la vieja idea de "recuperar" los espacios quitados por los gobiernos liberales en el siglo XIX, tales como Popayán, Santa
Marta, entre otros, preocupándose por abrir nuevos horizontes y nuevos espacios, aunque siempre tenía en cuenta el esplendor pasado.

Dos proyectos suyos merecen ser rescatados, pues representaron los ejes de su accionar como constructor: el Convento de Santo Domingo y el Colegio de Santo Tomás de Aquino. También nos referiremos a su papel en la reorganización del estudio dominicano y sus controvertidas relaciones con los dominicos franceses que arribaron a la Provincia.

\section{El nuevo convento de Santo Domingo}

Una de las grandes obras de Ariza fue la construcción del nuevo e imponente convento de Santo Domingo, lo cual expresa la idea de "expansión" y magnificencia que él tenía para la Orden en Colombia. Muchos no saben, por otra parte, que detrás de su construcción hubo toda una controversia.

La comunidad, desde la década de 1910, tenía un lote en el sector de Marly, destinado a la construcción de una Iglesia y un convento de estudios que reemplazara el viejo edificio del centro de Bogotá, expropiado por el Gobierno en 1861 y nunca devuelto. Por falta de fondos la edificación del nuevo convento se había demorado varias décadas. Por su parte, Ariza, al llegar al provincialato, tenía en mente construir el Colegio de Santo Tomás, con la intención de restaurar la Universidad. Para ello no tuvo inconveniente en utilizar, de manera inconsulta, el terreno de Marly para ese propósito. ¿Dónde se construiría entonces el nuevo convento y con qué recursos? Sencillo: vendió el viejo templo de Santo Domingo, al lado del extinto convento, el cual se encontraba en muy malas condiciones físicas. El gobierno nacional, por su parte, había estado presionando para que se vendiera dicha edificación. 
Esto lo hizo cuando ejercía el cargo de vicario provincial, hacia 1946. De acuerdo con Báez, "asumió todos los derechos de provincial, lo que está inhibido a los vicarios, quienes deben reservar al futuro, los casos más graves. Por eso vemos, que habiéndose presentado el affaire de vender el templo de Santo Domingo de Bogotá, se dice que se aprobó un consejo provincial sui generis y con él procedió, asegurándose con la previa aquiescencia de Roma" (Báez, ¿1950?, p. 520).

Así, mientras se destruía el colonial templo de Santo Domingo, Ariza buscaba un terreno alto, que dominara la ciudad, donde proyectó un edificio amplio y grandilocuente, pero a la vez austero y silencioso, que invitara al estudio y la contemplación. Construir Santo Domingo lo hizo contra el parecer de muchos y fue el proyecto de su vida. Incluso, el convento que debía llamarse "Nuestra Señora del Rosario", pues se trataba de un cambio de sede del convento fundado en 1551, no de la creación de uno nuevo, él comenzó a llamarlo "Santo Domingo", como indicando que iniciaba una nueva época para la Orden.

Muchos se opusieron a la creación de este convento como casa principal de estudios y sede provincial, porque pensaban que con ello se abandonaba el apostolado mariano tradicional en Chiquinquirá. En este proyecto, Ariza fue apoyado por los franceses Fr. Gabriel María Blanchet O.P. y Fr. Juan Bautista Nelly O.P. cuando ellos fueron provinciales. De hecho, la construcción del nuevo convento fue adelantada en gran parte por este último, quien también veía inadecuado como sede del noviciado y del estudiantado a Chiquinquirá, un pueblo ruidoso, lleno de peregrinos y romería, con todas las consecuencias e implicaciones adicionales que esto traía para una formación en disciplina, estudio y silencio.

Ello generó muchas críticas de parte de frailes de edad madura, quienes veían en estos cambios tan impetuosos un abandono a las orientaciones tradicionales y sentían miedo. En ello coincidía Fr. Enrique Báez, quien en su obra histórica recrimina a Ariza de haber gobernado "sin los viejos".

\section{Construcción del Colegio de Santo Tomás y restauración de la Universidad}

En su afán de proyectar la Comunidad hacia sus orígenes intelectuales, Ariza dio impulso al viejo proyecto de hacer renacer la Universidad Santo Tomás, clausurada en 1861, y para ello, como un primer paso, ideó la creación de un colegio de estudios secundarios, bajo el mismo nombre, lo cual rápidamente comenzó a cristalizarse en 1943 con la creación del Liceo Frassati y un año más tarde, con el inicio de la construcción del Colegio Santo Tomás.

Ese proyecto generó las controversias mencionadas por la manera inconsulta como se cristalizó.

Por otra parte, Ariza no estaba a favor de que la universidad renovada fuera administrada por los frailes directamente. En una opinión compartida con otros, quería que dicha administración estuviera a cargo de seglares de confianza, como los Terciarios Dominicos, por entonces fuertes y organizados, pues veía, de manera muy certera, que la administración distraía de los asuntos centrales en la vida de un fraile: la contemplación, la predicación y el estudio. Un fraile nos refiere al respecto:

A mí concretamente en 1960 me nombraron en la comisión, exploradora de la posibilidad de fundar la universidad; cada uno iba diciendo su punto de vista: que es un campo bellísimo y que es muy propio para nosotros, pero, dije, la universidad no la dirijan los frailes, dénle la administración a seglares de 
confianza que existían en ese tiempo, como los terciarios dominicos (...)

Bueno, entonces, las razones: porque en ese tiempo reinaba la idea en toda la Orden de que la administración, distraía mucho y demasiado en la evangelización y es cierto. Entonces nosotros, concretamente el padre Ariza y muchos jóvenes disentimos (...) pero el padre restaurador de la universidad, el padre Torres -fue connovicio mío- no lo pensaba así (...). Bueno, conclusión: no me volvieron a citar a mí a esas reuniones.

(...) Ariza, entonces se desilusionó y por eso él no podía ver ese modo de orientar, no porque no la quisiera sino porque estuvo demasiado orientada administrativamente por la comunidad, cosa que a él lo distraía... ${ }^{17}$

Ariza no concebía la Universidad Santo Tomás como una institución perfilada hacia lo civil y al mundo comercial e industrial. El tenía una fuerte añoranza por el pasado colonial, por la escolástica y el tomismo y quería que el centro educativo restaurado continuara dicha tradición. Por ello, nuestro fraile se abstuvo de continuar participando del proceso de restauración y se alejó del centro educativo una vez comenzó a funcionar.

Yo pienso que él se sintió desilusionado. Él seguramente si pensaba en un futuro la restauración de la universidad, con un proyecto a mediano plazo, dentro de unos criterios muy rígidos y muy eclesiásticos de restauración. Yo creo que él tenía amigos y tenía la fuerza suficiente para haberlo hecho, pero tal vez no tuvo tiempo; entonces, por una parte, que él no haya sido el autor material de la restauración, puede haberlo contrariado y luego, digamos, el criterio realista que optaron los restauradores fue abrir carreras civiles y darle a la universidad una estructura, como universidad de los años 60 , no confesional (...) el padre Ariza logró experimentar una actitud mucho más de rechazo y de antipatía, frente al rumbo que tomó la universidad, un ritmo muy secular y donde ya el tomismo no tenía gran referencia ni la misma filosofía y teología, fueron concedidas como programas banderas de la universidad, sino ingenierías y carreras laicas. ${ }^{18}$

El propio Ariza advierte a la Universidad, al final de un ensayo sobre su historia, lo siguiente:

Renacen nuestro Colegio y nuestra Universidad en medio de una expectativa general. Gran satisfacción por el anhelo cumplido, pero grave compromiso. El aggiornamento de nuestros días hace halagadoras invitaciones: relajar los valores tradicionales en busca de más aire, más luz; el cientifismo pide sólo se admita lo que la ciencia pueda demostrar (...) el antropocentrismo aspira a suprimir las aspiraciones trascendentales y que el hombre halle en sí mismo su perfección y su destino; el secularismo impulsa a suprimir de la vida la abnegación y el sacrificio adaptando un cristianismo 'sui géneris' con la comodidad mundana, que llevará necesariamente al afán del dinero, el desvío de la fe, la condenación eterna (...)

(...) A estos vientos de falsa cristiandad, nosotros, a ejemplo de nuestros antepasados de cuyas glorias nos ufanamos, debemos oponer resueltamente la tradición católica, enriquecida con el aporte de una herencia familiar a la que tenemos que ser fieles, so pena de grave indignidad. Nuestra Orden no es escuela de enciclopedistas (...) desde que nos volvimos enciclopedistas pedimos profundidad y vamos ganando mucho en superficialidad (...).

(...) No podemos ser oficiales de una empresa, acaso deslumbrante por aparente prosperidad, pero arrasadora de 
nuestro característico apostolado. La gloria de Dios, el honor de la Iglesia, el prestigio de nuestra Orden exigen la guarda del tesoro de nuestra tradición (...)." (Ariza, 1993, p. 2, 1487)

\section{La formación de los frailes y las relaciones con los dominicos franceses}

Este aspecto es muy interesante en la medida que determinó el rumbo de la orientación intelectual, teológica e ideológica de los dominicos colombianos.

Debido a que la provincia, tras varias décadas de su restablecimiento formal no mostraba signos de un avance significativo, sobre todo en materia disciplinaria, pastoral y académica, el Maestro General de la Orden decidió, a fines de la década de 1930, enviar un grupo de frailes de nacionalidad francesa, reconocidos por su dinamismo y vanguardismo. Este grupo lo encabezaba Fr. Gabriel María Blanchet O.P. Luego llegaron Fr. José León Maureau O.P., y Fray Juan Bautista Nelly O.P., entre otros. Ellos se encargaron de dirigir los distintos niveles de formación de la provincia dominicana, enfatizaron especialmente el noviciado y la formación laical. Al parecer, su llegada contó con el visto bueno de Ariza, y en un comienzo hubo buena "sintonía", pues, sabemos, aunque tenía el tema de la formación en su agenda, él mismo no tenía experiencia en ella, por lo que inicialmente no tenía razones para controvertir con los galos. “Él (Ariza) le dejó eso a los franceses, la formación de novicios, estudiantes y a través de los seglares; por eso, y yo creo que él no estaba en contra, el gran trabajo que hizo con seglares."19

Con ellos, bajo la mirada aprobatoria de Ariza, se impulsó además una renovación de la vida comunitaria, se trabajó en aspectos tales como la liturgia dominicana, que es muy rica y diversa. Antes de su arribo, cuenta Sedano, los frailes viejos afirmaban que "la única escala coral que conocíamos eran las escaleras del coro al segundo piso", y que "no tenían idea de la misa conventual".

Por eso el padre Ariza y sobre todo el padre Blanchet, lucharon para que todos participaran, incluso, sacerdotes, estudiantes y novicios; una misa conventual muy fraterna. Claro, en ese tiempo no había misa concelebrada y cada uno terminaba el oficio y se iba a decir su misa donde fuera; entonces el padre Ariza luchó muchísimo sobre todo para la misa conventual, que fuera realmente la misa como una Eucaristía, como dice las constituciones, que fuera el corazón de la misma comunidad, que explota (...). ${ }^{20}$

Ariza tenía una concepción romántica de la restauración francesa del siglo XIX, liderada por Fr. Enrique Lacordaire O.P (1802-1861) y consideraba que los religiosos galos traerían algo que la provincia dominicana de Colombia no tenía: disciplina y proyección. Sin embargo, un inevitable conflicto político-religioso se presentó, agravado por choques culturales.

En primer lugar, este grupo francés estaba imbuido en las corrientes de vanguardia, controvertidas por entonces, pero que más tarde orientarían la doctrina del Concilio Vaticano II. Dichas corrientes enfatizaban una apertura de la Iglesia al mundo moderno y una concepción del laico como miembro activo de la comunidad eclesial. En segundo lugar, su eurocentrismo los hacía mantener una concepción pobre y limitada de la sociedad colombiana, sobre todo de los grupos populares y campesinos, mayoritarios en nuestro país por entonces. Tampoco tenían buen concepto de la pastoral dirigida a fomentar la religiosidad popular, como se llevaba hasta el momento. Tengamos en cuenta, finalmente, que la mayoría de los frailes colombianos de entonces, además de conservadores e integristas, procedían del medio rural y de familias 
de escasos recursos. Ahora, con estos ingredientes había un caldo propicio para los roces.

El clero europeo era muy apetecido por los obispos, debido a su mayor preparación y organización y esto no dejaba de originar celos y envidias por parte de los clérigos colombianos. Fr. Enrique Báez -uno de los primeros historiadores de la provincia restaurada- por ejemplo, los acusaba de que "siempre quieren gobernar al (clero) nacional, y nunca se posesionan íntimamente de las necesidades de la región". También les disgustaba, que salvo los españoles, en general no les llamaba la atención imbuirse en las luchas contra el liberalismo, a lo cual eran muy aficionados los eclesiásticos colombianos. Finalmente, dejaban entrever algo de resentimiento, se les consideraba desagradecidos y poco generosos:

Por caridad no lo calificamos de egoísta (al clero extranjero), pero cuando uno va a Europa por ejemplo, en donde no se le ofrece a uno ni un vaso de agua; en cambio cuando ellos vienen entre nosotros los amamos y atendemos y les damos hasta el alma (Báez, ¿1950?, p. 520)

Por todo ello, Ariza, dueño de una personalidad fuerte, absorbente y autoritaria, entró en conflictos con ellos, especialmente con Fr. Gabriel María Blanchet O.P., a quien más tarde, si bien le reconoció su "cultura teológica superior", lo calificó de temperamental y explosivo, afirmaba que había sido un error haberlo hecho provincial (Ariza, 1993: 2, 1333).

Fr. Carlos Mario Alzate, historiador, nos ilustra sobre el desarrollo del conflicto ideológico entre Ariza y los franceses:

Yo creo que eso era un conflicto ideológico, porque en lo personal él fue quien promovió al menos en el primer momento que ellos vinieran y el que les colocó en un puesto delicado de la provincia; pero yo me imagino que su accionar en Colombia, que en un comienzo fue bastante notorio, por la elite, intelectual y social a la cual ellos (los franceses) se dirigieron y por la manera como ellos empezaron a trabajar con la Acción Católica (sic) una fraternidad de tipo Testimonio que de alguna manera como que avisó a lo que vendría a ser el Concilio Vaticano II el papel del laico en la Iglesia, con la formación que ellos quieren impulsar en Chiquinquirá y luego con los provincialatos de dos de los que venían, que me imagino que no estaba previsto desde el comienzo, se fue creando un vacío, un abismo irremediable entre el padre Ariza y el grupo. Los franceses se fueron de alguna manera como capitalizándose en toda la provincia, sobre todo en la gente joven, para un futuro, su proyecto de fundación en otra parte del país (Antioquia), cuando ellos vieron que la provincia los aceptaba a ellos como colaboradores, pero no querían que fueran como reformadores al interior de la misma provincia.

De tal manera que, pienso que el conflicto más que personal, auque puede tener ribetes personales, tiene mucho más que ver con la actitud vanguardista que tomaron los franceses y con el peligro que empezaron a entrañar, cuando ellos empezaron a conseguir el proyecto de crear con gente joven y frailes un poco en la línea de ellos una entidad nueva, distinta, volcada sobre todo a una visión popular y cuando, por ejemplo, abrieron la casa de ellos, al sur de Bogotá en el barrio San Vicente Ferrer, que era una acción absolutamente inédita, querían hacerse cargo de una misión en el Chocó, en el Atlántico y me refiero que el padre Ariza tenía una visión más señorial de la Provincia, más apegada a la Basílica de Chiquinquirá y a los colegios; de pronto él estaba pensando en fundar y veía como sospechoso y peligroso 
para la provincia, hacer presencia en sectores populares, con obras que aparentemente no iban con el carisma, ni con el perfil que en ese momento se tenía de un fraile predicador ${ }^{21}$.

Como se dijo, los franceses también orientaron su acción hacia el apostolado laical por medio de las hermandades dominicanas. El padre Nielly, por ejemplo, fue el asesor de una hermandad compuesta por laicos profesionales de estrato alto, llamada "Hermandad de Santo Tomás de Aquino", con la cual creó la Revista Testimonio, alrededor de la cual agrupó a líderes que expresaban propuestas político religiosas alternativas a la época y que chocaron con nuestro rígido medio bipartidista en lo político y tradicionalista en lo religioso (Escobar, 2008).

Sin embargo, Ariza no quiso ir más allá, cuando vio que se desencadenaban procesos que él no podía controlar. Un testimonio dice que: "nosotros que nos formamos en la línea del padre Blanchet, por consiguiente, que desembocamos en el Concilio Vaticano II, nosotros tuvimos problemas por esa línea a (...) y a otros tres nos echaron (...)." 22

Se refiere al "extrañamiento" temporal, sucedido en 1965, de él y otros dos compañeros frailes que pensaban en la línea vanguardista iniciada por los franceses.

La copa rebosó cuando, los mencionados dominicos galos, desilusionados por la lentitud en los procesos generados y la resistencia que se les prestaba por parte de los frailes tradicionalistas, idearon crear un vicariato dominicano separado en la región antioqueña, sin consultar con el Maestro de la Orden. Para Ariza fue la oportunidad que buscaba: por medio de sus excelentes contactos, azuzó la hoguera, los acusó ante las autoridades romanas y gestionó su intempestivo y fulminante retiro ${ }^{23}$, al mismo tiempo que él era elegido provincial por segunda vez.
Este hecho ocasionó mucha decepción entre los novicios y estudiantes, quienes estaban encantados por el estilo de formación impartida por los franceses. Así lo afirmó un religioso dominico en su entrevista:

\section{Fr.: ¿Usted se siente defraudado?}

$\mathrm{R}$ : Si, es decir, defraudado, porque (Ariza) nos quitó a los que eran reformadores, que él mismo había contribuido a traer y que les ayudó a integrarse en nuestra provincia; esa fue la gran contradicción, le agradezco porque para mí y para muchos de nosotros, la presencia del padre Blanchet. Yo en mis libros que he publicado, por ejemplo, La Pedagogía de la Respuesta, la saqué y la aprendí al padre Blanchet ${ }^{24}$.

Así, un proceso que pudo haber cosechado muchos frutos quedó trunco. Se puede en este punto reflexionar si constituye algo propio de nuestra idiosincrasia generar y echar a andar ambiciosos proyectos, de manera entusiasta, para luego asustados ante las primeras dificultades, frenar y dar un viraje hacia el lado contrario. Lo decimos, pues casos como este se han repetido a lo largo de nuestra historia, en diferentes ámbitos y sectores.

\section{Escritor e historiador}

Otra faceta suya muy importante, fueron sus dotes como ensayista e interés por el campo de la historia. Ya desde sus tiempos de estudiante colaboró en la revista Algores, publicación de los frailes estudiantes del momento $y$, más tarde como joven sacerdote, dirigió el polémico semanario Véritas órgano del Santuario de la Virgen del Rosario de Chiquinquirá (Téllez, 1993:24).

Ariza, que solía matizar sus escritos con frecuentes y contundentes frases en latín, se caracterizó por su gusto por las polémicas académicas, intelectuales 
y políticas. Al respecto, Fray Luis Téllez afirma de Ariza que era:

periodista de garra y de lanza, investigador histórico sagaz y penetrante. Versadísimo en asuntos historiales de la Orden en América, especialmente de Colombia. Autodidacta, eterno estudiante y estudioso de laboriosidad ejemplar, benemérita y constante" (Téllez, 1993, p. 24).

Ariza escribió numerosos ensayos y una extensa obra que pretendió recopilar los principales hitos de la historia de los dominicos en nuestro país ${ }^{25}$, resaltando sus aportes y enalteciendo su labor, especialmente durante la Colonia, considerada por él como la época "dorada" de la Orden en nuestro país, notándose además, una nostalgia por ese pasado "glorioso". Precisamente uno de sus propósitos al incurrir en la historia era buscar infundir entre los frailes de su generación, la necesidad de engrandecer de nuevo a la entonces alicaída Provincia dominicana. Fue un apologeta de su comunidad religiosa, que salió a relucir en momentos álgidos, por ejemplo, cuando tras la destrucción del antiguo templo de Santo Domingo en el centro de Bogotá, la comunidad dominicana fue acusada de negligencia. La pluma del Ariza apareció, acerada y cortante, defendiendo el honor de los frailes.

Fray Alberto, en este campo, fue cofundador y miembro del Instituto de Cultura Hispánica (hoy Instituto Colombiano de Antropología e Historia) y de la Academia de Historia Eclesiástica y perteneció a otras academias y centros de investigación, como la Academia Colombiana de Historia.

Su obra, si bien se realizó de acuerdo a los parámetros propios de la historia tradicional y academicista, constituye un gran aporte factual valioso para un futuro ejercicio de análisis de la labor de los dominicos en Colombia.

\section{El concilio y el post-concilio}

Fr. Alberto Ariza amaba el orden, la disciplina y examinaba su mundo desde la tradición. Por eso sufrió mucho cuando, a partir del Concilio Vaticano II, la comunidad y la Iglesia entera ingresó en un período de inestabilidad y crisis, bajo las consignas de "reevaluación" e "innovación", cuyas exageraciones denunció. Frecuentemente decía que intereses mundanos y malignos minaban la Iglesia bajo la palabra "aggiornamento", tan utilizada entonces. No dejó de lanzar sátiras contra esa situación al ridiculizar dicho término.

Si la generalidad del episcopado y buena parte del clero colombiano de la época tuvo dificultades para comprender el Concilio Vaticano II, es claro que Fr. Alberto Ariza no fue capaz de aceptarlo. El Concilio fue para él un baldado de agua fría. Un fraile nos cuenta sobre ello:

$\mathrm{Si}$, yo veo precisamente, la personalidad tan paradójica del padre Ariza, un hombre tan renovador, en la provincia, que no se contentó con la tradición pastoral y pastoralista de la restauración de la provincia, llega el Vaticano II y se encierra, se cierra completamente a las nuevas orientaciones; eso se le notaba al padre Ariza desde antes. Claro, formados nosotros por el padre Blanchet, teníamos ciertos encontrones con él (...).

(...) Claro que siguió queriendo la Orden y una vez me dijo: 'iAy! ¿Pero cómo quiere que sea y yo?' le dije: ‘Padre, cómo si usted fue un revolucionario en su provincialato: ¿Por qué ahora que llega el Vaticano II usted se queda ahí?. Me dice: 'es que esto es demasiado adelantista (sic); con todo, yo sigo queriendo la Orden arrugada $y$ todo $(. . .)^{26}$

A partir de entonces una concepción fatalista sobre la suerte de la Iglesia y de su querida Orden Dominicana se adueñó 
del espíritu de nuestro fraile. Hacia 1974, cuando la crisis postconciliar marcaba sus puntos más álgidos y muchos habían desertado de la Orden y hasta de la Iglesia, Fr. Alberto escribió al Maestro General una carta donde achacaba dicha crisis al abandono a la tradición y la apertura alegre e irreflexiva a las ideas modernas. Veamos algunos apartes:

En primer lugar, él mismo se consideraba como perteneciente al pasado, como uno de los últimos portadores de la verdad, despreciada por todos los "modernos".

Aproximándose al Capítulo General, en el cual serán ratificadas las nuevas constituciones de la Orden, había pensado, en uso del derecho, colaborar con algunas observaciones. Pero pensándolo despacio, y recordando que las observaciones de los "amargados y retardatarios" no son tenidas en cuenta, he resuelto no formularlas... ${ }^{27}$

Achacaba la crisis en la Orden a los propios dirigentes de la misma, a quienes consideraba "cómplices activos" por la introducción de reformas que relajaban la disciplina regular.

Yo lamento sinceramente que la tragedia haya acontecido durante el Generalato del P. Aniceto (Fernández), español por añadidura. La Orden hoy, en gran parte, no es sino congregación de unos clérigos volantes para quienes el convento no es sino una hospedería; la Orden ha quedado prácticamente sin fin específico en la Iglesia; suprimido prácticamente el magisterio de Santo Tomás, menospreciado el latín en el estudio de la filosofía y de la teología, y en la liturgia, con aspirantes a dominicos formándose en escuelas que nada tiene que ver con la Orden y en ambientes adversos a nuestra tradición. ¿Qué podrá esperarse? El recurso de echarle la culpa a la crisis universal (de la Iglesia) no logra engañar siquiera a los mismos que lo alegan. ${ }^{28}$

Afirmaba que la vida dominicana había desaparecido "con la desacralización y la democratización de la obra de Santo Domingo. Los frailes mundanizados dizque para ser más ágiles apóstoles de Cristo!"

Veía que el mundo por el cual él había luchado se acababa y que después de esto, difícilmente habría una recuperación: "El desmonte sistemático adelantado durante ocho años (1965-1973) no tiene fácil reparación. Que Dios haga eficaz y constante la voluntad de quienes anhelan la rectificación (...) iQue Dios sea nuestro consuelo en esta intensa amargura!"29.

Y amargura fue lo que el padre Ariza experimentó hasta su muerte, ante los caminos que tomaba su Orden, sobre todo porque él no podía hacer nada para detener los procesos y no había un enemigo visible a quien enfrentar, como antaño. Alzate nos dice al respecto:

Ariza ya era un hombre que había combatido mil batallas, que le había costado todo un proyecto de provincia, como él lo concebía, que veía que esta hoja de cambios, llegaba con una rapidez inusitada y que hacía mella notable en las generaciones jóvenes (...). Por eso, toma esa actitud de cerrarse y de permanecer al margen de los cambios que se operaban (...) yo pienso que el padre Ariza acostumbrado a batirse allí con un adversario determinado visible, de igual a igual, o cargo político o eclesiástico ve esto como un desmantelamiento general, que yo creo que se siente impotente, ¿Contra quien va a escribir? No hay contra quien combatir. Por todas partes que se entró el modernismo y la relajación de costumbres y la visión diferente de la vida religiosa. Simplemente vio que no podía combatir, que no sabía, como que no tenía un enemigo ubicado (...)..$^{30}$ 
Ariza quedó viviendo su soledad en el inmenso Convento de Santo Domingo, que prácticamente se desocupó a partir de 1968.

R: Por eso yo creo que le padre Ariza sufrió muchísimo.

\section{P: ¿Mucha soledad?}

R: Soledad si, porque, claro, encontraba en el ambiente de los jóvenes y de los padres ideas completamente distintas a las de él, incluso teológicas.

P: Además el mismo Santo Domingo, todo ese convento para pocos frailes, porque: iLa mayoría se fue $!^{31}$

Después, desde el Convento de San José, en Bogotá, su nuevo "refugio", que dirigió y convirtió en un lugar muy suyo, continuó en la misma tónica, repetía sin cesar, junto con algunos frailes que le hacían coro, "la idea suya de que la Provincia estaba decadente y había que luchar contra el sismo y contra el aburguesamiento y contra la mundanidad que se había introducido en la provincia por culpa de la Universidad." 32 Incluso, según Alzate, el Convento de San José, mientras él vivió allí, fue bastante refractario a la Universidad Santo Tomás y mantuvo una postura de conflicto y aislamiento con otras entidades de la Provincia ${ }^{33}$.

\section{La puesta del "sol"}

La salud de Fr. Alberto no fue muy buena a lo largo de su vida, y cuando la vejez hizo su arribo, sus achaques se acrecentaron. A partir de su tercer provincialato (1953-1957) fueron constantes sus visitas al hospital, y en más de una oportunidad, hizo creer a sus hermanos y hermanas que se marchaba de este mundo. Aún así no dejaba a un lado su espíritu combativo, como afirma fr. Germán Correa: "tuvimos incluso oportunidad de recibir de él mensajes incisivos, telegrafiados ya desde la barca de Caronte" (Correa, 1987, p. 4).
A comienzos de la década de 1980, Fr. Alberto no da más, tuvo que dejar la única labor de la cual no se había marginado: la historia. Su última publicación fue una reseña histórica de la Universidad Santo Tomás, pero su gran obra, la crónica de la Orden de Predicadores en Colombia, que durante varios años preparó, debió dejarla inconclusa. Pasó sus últimos años de vida en Fusagasugá, en la casa de las Hermanas Dominicas de Nazareth, atendida por la Hna. María Luisa Quiroga O.P. Finalmente, las enfermedades llevaron sus huesos al sepulcro, a fines de mayo de 1987.

A 25 años de su muerte, el clima creado por la animosidad que se produjo en torno a él no se ha disipado del todo $y$, por ello, no se ha realizado un estudio más o menos profundo sobre su vida, que trascendió el plano de la Orden, convirtiéndolo en una figura representativa de la institución eclesiástica colombiana, especialmente durante los años 40 y 50 . A pesar de sus polémicas y choques, la vida y labor de Fr. Alberto Ariza no pasa desapercibida. Gran parte de la estructura actual de la provincia dominicana se debió a su dinámica gestión, a su fuerte personalidad, a su tezón y temple.

Un día, cuando nuestro fraile, en plena ancianidad, se encontraba refunfuñando de su suerte y la de la Orden, un religioso le dijo: "Padre Ariza, su vida no está perdida. ¿Sabe por qué? Porque usted no solamente escribió historia, sino que hizo historia (...)." 34

\section{Notas}

${ }^{1}$ La Orden de Predicadores, presente en lo que hoy es Colombia desde 1529 , conoció durante la época colonial una gran influencia en todos los órdenes, fue uno de los bastiones de la sociedad, Estado e Iglesia coloniales. Sin embargo, tras la Independencia, sobrevino una fuerte crisis interna, que, aunada a los esfuerzos guberna- 
mentales por debilitar las otrora poderosas órdenes religiosas, conllevó en 1861 a la supresión de la comunidad dominicana como corporación pública y la confiscación de todas sus propiedades, dentro del proceso conocido como "desamortización de bienes eclesiásticos" (1861-1864), ordenado por Tomás Cipriano de Mosquera durante su segunda administración.

2 Entrevista a Fr. Carlos Mario Alzate O.P. Bogotá, 22 de marzo de 2003.

${ }^{3}$ Entrevista a Fr. José de Jesús Sedano O.P. Bucaramanga, 3 de mayo de 2003.

${ }^{4}$ La iglesia de Santo Domingo, parte del antiguo convento de Nuestra Señora del Rosario de Bogotá, fue demolida en 1946, luego de que los dominicos la vendieran, debido a su estado ruinoso y ante la imposibilidad física de reconstruirla y restaurarla. Su venta y demolición provocó gran escándalo en la sociedad capitalina de entonces.

${ }^{5}$ Entrevista a Fr. José de Jesús Sedano (...).

${ }^{6}$ Desde la época colonial y hasta las primeras décadas del siglo XIX fue práctica común llevar infantes a los conventos. Muchos de ellos eran parientes de frailes, quienes se encargaban de su educación básica, a la vez que los tomaban como amanuenses. Estos niños representaban potencialmente nuevas profesiones a mediano plazo (Plata, 2008: 66; Esparza, 1996:273).

${ }^{7}$ Convento rural creado en el siglo XVII en inmediaciones a la Villa de Leyva, en Boyacá. Fue utilizado varias veces como lugar de recogimiento, retiro y hasta de reforma. Fue suprimido en 1821 por el gobierno de Francisco de Paula Santander y restaurado por corto tiempo en la década de 1850. Luego fue suprimido de nuevo y expropiado en 1861. A comienzos del siglo $\mathrm{XX}$ los dominicos lo volvieron a adquirir e intentaron crear comunidad conventual formal en varias ocasiones, sin éxito. Funcionó luego como casa de encuentros, de convivencias y de retiros espirituales. Un siglo más tarde, el convento sirve de museo y atractivo turístico. El edificio es una de las joyas coloniales que se conservan en nuestro país.

8 Tras la destrucción del claustro del antiguo convento colonial de Nuestra Señora del Rosario (1939) y de su iglesia (1946), Ariza, a la postre, vicario provincial de los dominicos, decidió construir un nuevo edificio conventual en otro sitio de la ciudad, el cual se inauguró en 1953.

${ }^{9}$ Para Ariza, un convento debía ser “bello, amplio y acogedor, digno de su función: mentibus corporibusque requires, evocador de la tradición de la Orden y creador de un ambiente de tranquilidad que promueva el estudio y la superación personal. Asimismo, el convento debía estar "convenientemente alejado del ambiente mundano". (Ariza, 1993:1, 527)

${ }^{10}$ Entrevista a Fr. Carlos Mario...

${ }^{11}$ Entrevista a Fr. José de Jesús Sedano.

12 Aún se recuerda la Revista Testimonio, muy influente en la década de 1950, y que contaba con el apoyo de un pequeño grupo de dominicos partidarios de una apertura en el diálogo Iglesia - Mundo. (Escobar, 2008:125154).

${ }^{13}$ Entrevista a Fr. José de Jesús...

${ }^{14}$ Entrevista a Fr. Carlos Mario.

${ }^{15}$ Entrevista a Fr. Carlos Alfredo Alarcón O.P. Tunja, 10 de diciembre de 2001.

${ }^{16}$ Carta de Fray Alberto E. Ariza a la M. R. Madre María Teresa de Santa Catali- 
na de Sena. Bogotá, 14 de febrero de 1961, en Archivo General de la Congregación Hermanas Dominicas de Betania (Bogotá, en adelante AGDB), Tomo 2, Folio 28.

${ }^{17}$ Entrevista a Fr. José de Jesús...

${ }^{18}$ Entrevista a Fr. Carlos Mario...

${ }^{19}$ Entrevista a Fr. Carlos Mario...

20 lbíd.

${ }^{21}$ Entrevista a Fr. Carlos Mario...

${ }^{22}$ Entrevista a Fr. José de Jesús...

${ }^{23}$ Entrevista a Fr. Carlos Mario...

${ }^{24}$ Entrevista a Fr. José de Jesús... p. 3.

${ }^{25}$ Según el periódico “Veritas", Fray Alberto Ariza publicó más de 71 obras, entre libros y folletos, sin mencionar los centenares de artículos y ensayos que escribió: (Anónimo:1981).

${ }^{26}$ Entrevista a Fr. José de Jesús...

${ }^{27}$ Carta de Fr. Alberto Ariza al Maestro General de la Orden. Bogotá, 4 de marzo de 1974. en APCOP, fondo San Antonino, sección Provincia - Fr. Alberto Ariza O.P. unidad temporalmente sin codificación, Fol. 270.

28 lbíd.

29 lbíd.

${ }^{30}$ Entrevista a Fr. Carlos Mario... p. 7.

${ }^{31}$ Entrevista a Fr. José de Jesús...

${ }^{32}$ Entrevista a Fr. Carlos Mario.

33 /bíd.

${ }^{34}$ Entrevista a Fr. José de Jesús Sedano.

\section{Archivos}

- Archivo de la Provincia Dominicana de San Luis Bertrán de Colombia (Padres Dominicos. Bogotá, Colombia. APCOP.
Fondo San Antonino, sección Provincia - Fr. Alberto Ariza.

Fondo San Antonino, sección Colecciones - Baeza

- Archivo General de la Congregación Hermanas Dominicas de Betania (Bogotá, Colombia) AGDB

Tomo 2

\section{Fuentes orales}

- Entrevista a Fr. Carlos Alfredo Alarcón O.P. Tunja, 10 de diciembre de 2001.

- Entrevista a Fr. Carlos Mario Alzate O.P. Bogotá, 22 de marzo de 2003.

- Entrevista a Fr. José de Jesús Gamboa O.P. Fusagasugá, 3 de agosto de 2003.

- Entrevista a Fr. José de Jesús Sedano O.P. Bucaramanga, 3 de mayo de 2003.

- Entrevista a Fr. Tomás Monsalve O.P. Bogotá, 12 de diciembre de 2001.

- Entrevista a Hna. María Luisa Quiroga O.P. Fusagasugá, 10 de agosto de 2003.

\section{Referencias}

ANÓNIMO "BODAS DE ORO SACERDOTALES. R. P ALBERTO E. ARIZA SÁNCHEZ, OP" Veritas, 2867. Chiquinquirá: 29 de noviembre de 1981.

ARIAS, Ricardo (2003) El episcopado Colombiano, intransigencia y laicidad (1850 - 2000), Bogotá UNIANDES/ICANH.

ARIZA, Alberto O.P. (1960) Anclados en el pasado. Bogotá. (inédito).

ARIZA, Alberto O.P (1993) Los dominicos en Colombia. Tomos 1 y 2. Santafé de Bogotá: Provincia de San uis Bertrán de Colombia.

BÁEZ, Enrique O.P. (¿1950?) La Orden Dominicana en Colombia. Tomo VIII. (s.I.) (Inédito)

CIFUENTES, María Teresa y Figueroa, Helwar (2004) "Corrientes del catolicismo frente a la guerra y la paz en el siglo $X X^{\prime \prime}$ en Ana María Bidegain (dir.) Historia del cristianismo en Colombia. Corrientes y diversidad. Bogotá: Taurus.

CORREA, Germán O.P. (1987) Adiós al padre Ariza O.P. Véritas, $71-3076$

ESCOBAR HERRERA, Andrés. (2008) Una religión más vivida y una vida más religiosa. Testimonio: un movimiento de seglares en Colombia 1947-1957. Anuario Colombiano de Historia Social y de la Cultura, 35, 125-154

ESPARZA, Manuel (1996) Santo Domingo grande. Hechura y reflejo de nuestra sociedad. Oaxaca: Patronato Pro-defensa del patrimonio cultural y natural de Oaxaca.

PLATA QUEZADA, William Elvis (2010) Un análisis a la historia de los dominicos en Colombia. Articulación social y ciclos de vida Albertus Magnus. 3 - 2 . 
PLATA QUEZADA, William Elvis (2008) Religiosos y sociedad en Nueva Granada (Colombia). Vida y muerte del convento dominicano de Nuestra Señora del Rosario. Siglos XVI-XIX. Tesis Doctoral en Historia, Arte y Arqueología. Namur (Bélgica): Facultés Universitaires Notre-Dame de la Paix, Académie Louvain.

TÉLLEZ G. LUIS O.P. (1993) NOTICIA BIOGRÁFICA Y PENSAMIENTO RELIGIOSO DEL PADRE ALBERTO E. ARIZA SÁNCHEZ, O.P. en Alberto Ariza O.P. Los dominicos en Colombia. Tomo 1. Santafé de Bogotá: Provincia de San Luis Bertrán de Colombia. 